Revista Mídia e Cotidiano

Entrevista

Número 10, Dez. 2016

\title{
ECONOMIA POLÍTICA DA COMUNICAÇÃO, ESTUDOS CULTURAIS E \\ CIÊNCIA DA INFORMAÇÃO: uma entrevista com Armand Mattelart
}

\section{POLITICAL ECONOMY OF COMMUNICATION, CULTURAL STUDIES AND INFORMATION SCIENCE: an interview with Armand Mattelart}

\author{
Marco SCHNEIDER $^{1}$
}

Resumo: Armand Mattelart é um importante teórico e historiador da Comunicação Social. Autor de mais de uma dúzia de livros, incluindo Como Ler o Pato Donald (com Ariel Dorfman), História das Teorias da Comunicação (com Michèle Mattelart) e História da Sociedade da Informação, o sociólogo belga tem fortes relações com a América Latina e é uma referência no campo da Economia Política da Comunicação (EPC). Nesta entrevista, Mattelart é convidado a falar sobre os fundamentos epistemológicos da EPC, sua relação com os Estudos Culturais e a Ciência da Informação, seus compromissos éticos e a possível cientificidade desses compromissos. A entrevista termina com indicações bibliográficas sobre assuntos relacionados, incluindo um ensaio escrito por León Trotsky sobre a vida cotidiana.

Palavras-chave: economia política da comunicação; estudos culturais; ciência da informação; epistemologia; ética.

Abstract: Armand Mattelart is an important theorist and historian of Social Communication. Author of more than a dozen books, including How to Read Donald Duck (with Ariel Dorfman), History of Communication Theories (with Michèle Mattelart) and History of the Information Society, the Belgian sociologist has strong relations with Latin America and is a reference in the field of Political Economy of Communication (EPC). In this interview, Mattelart is invited to talk about the epistemological foundations of EPC, its relationship with Cultural Studies and Information Science, its ethical commitments and the possible scientificity of these ethical commitments. The interview is finished with bibliographic indications on related subjects, including an essay about everyday life, writen by León Trotsky.

Keywords: political economy of communication; cultural studies; information science; epistemology; ethics.

Entrevista realizada em La Habana, Cuba, em dezembro de 2015, com apoio do CNPq, como parte do projeto de pesquisa Ética, política e epistemologia: interfaces da informação, coordenado por Marco Schneider no âmbito do PPGCI-Ibict/UFRJ. A transcrição foi realizada por Rafael Zincone. A tradução foi realizada por Rafael Zincone e Marco Schneider. 
Schneider: Bom dia, Sr. Mattelart. Primeira questão: quais são os principais fundamentos epistemológicos da Economia Política da Informação, da Comunicação e da Cultura?

Mattelart: Então, eu creio que é preciso falar de maneira empírica, quer dizer, do ponto de partida da Economia Política Crítica ou, como prefiro dizer, da Crítica da Economia Política. Creio que o fundamento é esse e que foi construído progressivamente. Mesmo assim, devemos situar a Crítica da Economia Política com relação ao que existia anteriormente. Isso quer dizer que encontramos um campo de pesquisa que havia já sido construído pelo positivismo, pelo funcionalismo. Creio que isso é fundamental. E o início da crítica ao funcionalismo a partir da Economia Política crítica começa pela noção de ideologia, pelo investimento na noção de ideologia. Quer dizer: crítica ao "positivismo", ao "empirismo", à negação daquilo que chamaríamos de realidade de "segundo nível", de "segunda significação", como diria Barthes, como dizem todos os estruturalistas e não somente os estruturalistas. Acho que foi fundamental essa recuperação da noção de ideologia, tal como ela foi construída a partir de movimentos múltiplos desde Marx. Eu creio que isso foi importante e é por isso que eu penso que o começo, por exemplo, na América Latina, de uma reflexão crítica da Economia Política partiu daí. Bom, isso segundo sedimentações bem diferentes, porque Brasil, Chile e Argentina são bem diferentes. Há, a cada momento, condições de produção bem diferentes. Mas de todo modo, o que liga essas perspectivas é a noção de ideologia e de "segunda significação". Enfim, este é um primeiro ponto. Devemos situá-lo entre os anos de 1960 e 1970. Ora, nos anos de 1960 e 1970 houve uma renovação do marxismo de forma verdadeiramente plural. Possivelmente por influência de Althusser. Talvez também pela redescoberta de Gramsci (às vezes digo a mim mesmo que a redescoberta de Gramsci talvez tenha ocorrido mais tarde, nos anos 1970), quando se percebe que ocorreu uma verdadeira crise no marxismo. 
Além disso, houve interpretações muito diferentes de Gramsci. Quer dizer, de um lado Gramsci permitia o aprofundamento do marxismo e mais além, de outro era recuperado com a multiplicação de mediações ao ponto da noção de hegemonia perder seu lugar. Então, eu diria a você que os anos 1960 são importantes porque há ainda os marxismos ortodoxos que se instalam no campo científico. O estruturalismo não é monolítico. Podemos dizer que há contribuições múltiplas. Por exemplo, Lucien Goldman, que trabalha...

\section{Shneider: Lukács.}

Mattelart: Isso é fundamental. É interessante ver como Goldmann foi lido pelos Estudos Culturais britânicos. Sartre, tudo isso. Então, o que é interessante observar é a multiplicidade de cruzamentos daquilo que anteriormente caminhava de forma certamente unilateral. Acho que isso foi importante, mesmo através de homens como Althusser e sua escola, como Balibar, como Rancière etc. De todo modo, retoma-se Gramsci de novo. Não há como ler Althusser sem que se tenha em mente sua ligação com a noção de hegemonia de Gramsci. Mesmo se ele tem sua própria concepção, e creio que isso é importante, não se pode ler Althusser - A Favor de Marx, por exemplo - ignorando a noção que ele tem de hegemonia e que ele vai buscar em Gramsci.

Eu creio que, de qualquer forma, e apesar de todas as críticas que podemos fazer ao que denominávamos de teorias linguísticas (o estruturalismo linguístico), creio que se tratou de um momento importante de fundação de uma teoria crítica, mesmo de uma economia política. Porque eu acho que a pesquisa inicial, de fato, (e isso é muito importante para a América Latina) em Economia Política da Comunicação foi fundamentalmente tanto sobre as estruturas de poder quanto, finalmente, a ideologia. Creio que é isso que constituiu a força da pesquisa e, finalmente, a força do começo da Economia 
Política da Comunicação, o que não é o caso dos Estados Unidos. Nos Estados Unidos, Schiller, Guba, Dallas Smythe etc. não estudam o texto, nem sabem o que é o texto. Schiller, um pouco. Mas vamos dizer que isso não é uma tendência maior da Economia Política, tal como os americanos, Schiller e companhia, abordam a mídia.

É verdade que o estruturalismo linguístico gerou vários impasses e coisa e tal. Eu, quanto a isso, não tenho preconceitos. Afinal, foram produzidas coisas interessantes. Mesmo Barthes e seus discípulos, que em certo momento passaram para o outro lado, trouxeram importantes contribuições teóricas. É necessário ter a noção da construção de teorias múltiplas e bem combinadas, senão reduzimo-nos a uma concepção, a uma escola, como se diz. Por isso eu sou totalmente contrário à noção de escola. Porque eu acho que impede todo debate dialético.

Creio que as discussões nos anos 1960 e 1970 foram fundamentais para a revisão do marxismo. Participaram filósofos de múltiplas perspectivas. Imediatamente, penso em Adam Schaff, um dissidente político polonês. Foi também a redescoberta da Escola de Frankfurt. Há uma visão marxista que é crítica desde o começo, seja Benjamin, seja Adorno, seja Horkheimer. Para a construção de um novo tipo de marxismo isso foi fundamental. Podemos dizer hoje em dia: "ah, mas eles não foram bem-sucedidos no estudo de novos tipos de música, eles eram muito clássicos”, mas essa é outra questão. O que acho mesmo interessante é, em meio a isso, a redescoberta da pluralidade do marxismo. Creio que na América Latina isto está relacionado com Mariátegui. O que é muito importante, pois todas essas correntes são muito ocidentalistas. Mas o que é interessante é que o marxismo vai progressivamente se desocidentalizando. Há de fato um processo de desocidentalização do pensamento crítico nos anos de 1960, 1970. Uma desocidentalização pós-68. Desse ponto de vista, maio de 68, na França, é fundamental. 
Schneider: Mas além de Mariátegui, quem mais?

Mattelart: Na América Latina é Mariátegui. Mas não só ele. Tem por exemplo Paulo Freire, que no início não tinha nada de marxista. E Adolfo, como se chama...

Schneider: Sanchez Vasquez.

Mattelart: Sim, exatamente. Se consultamos as antologias (que são as melhores, de todo jeito), são de um marxismo que tem outra concepção de cultura, que não se confunde com a infraestrutura etc. Creio que há assim a redescoberta do marxismo heterodoxo. Há uma revista francesa muito interessante, $O$ Homem e a Sociedade, na qual irão convergir visões bem diferentes do marxismo, interpretações bem diferentes do marxismo -Althusser, por exemplo - a partir de latino-americanos. A partir dos anos 1960 e 1970, passa a haver cruzamentos nas concepções marxistas. Antes disso, havia hegemonia do pensamento ocidental.

E há finalmente a aparição dos Estudos Culturais. Que se constituíram a partir de sedimentações múltiplas. Temos por exemplo Goldman, Sartre, Lukács. O que é interessante no começo dos Estudos Culturais é a descoberta de um certo marxismo (não falo de Hoggart; Hoggart é muito interessante, mas ele não é marxista, pelo contrário, criticou bastante o marxismo). Mas eu pergunto: qual é de fato a originalidade dos Estudos Culturais? Eles nascem na Inglaterra. Nesse país, desde o início do marxismo, no século XIX, há um dos raros marxismos que favoreceu a utopia. O que vai contra a ideia de Marx de que as utopias estão em contradição com o socialismo científico. Isso é muito importante. A força de Williams e Thompson está precisamente em recuperar o marxismo em sua veia utópica. A gente não diz mais isso hoje em dia, mas é fundamental! Quer dizer, prosperou na Inglaterra um marxismo crítico ao marxismo 
vulgar, aquele que esqueceu a cultura, a subjetividade e todas essas mediações cotidianas. Isso é muito importante pois, em geral, os Estudos Culturais remetem à noção de hegemonia, mas não é só isso, é muito mais complexo. É uma corrente que nasceu na Inglaterra e, portanto, porta a marca do marxismo inglês. Não poderia ter nascido na França.

Deste ponto de vista, os Estudos Culturais foram fundamentais, pois retomaram o marxismo a partir de uma visão nacional que progressivamente se apagou. O drama dos Estudos Culturais não é tanto terem se desenvolvido no sentido de, em certo momento, abandonarem a economia e avançarem demais no consumo. Isso é um problema, certamente, mas o problema principal é que quando os Estudos Culturais britânicos passam para os Estados Unidos, perdem todo o terreno do qual emergiram e convertem-se em uma moda.

Schneider: Com exceção do Jameson...

Mattelart: Sim, claro, há exceções, mas não se pode afirmar que haja uma tendência, digamos, lógica. Isso é muito importante. Pois em dado momento os Estudos Culturais são esvaziados de sua substância. Com exceção de tipos como Jameson, conforme você mencionou...

Schneider: Douglas Kellner...

Mattelart: Sim. E outros. Há indivíduos. Porém, não posso afirmar que haja Estudos Culturais críticos nos EUA. É o que eu penso. Há núcleos, enclaves.

Schneider: Fale, por favor, da relação entre Economia Política da Comunicação e Ciência da Informação.

Mattelart: Creio que as Ciências da Informação nos dias de hoje são cada vez mais importantes. É a partir da aparição da noção de "informação" e de 
"documento" (no século XIX) que se constrói primeiramente uma Teoria da Comunicação. Assim, penso que a primeira Teoria da Comunicação é a Teoria da Informação. E refiro-me mesmo aos pioneiros da Ciência da Informação, como Otlet. Para eles, o documento é um elemento de universalização e solidariedade entre o povo. Isso é muito importante pois, na realidade, é o povo em primeiro lugar que cria a noção de mundialização. Essa noção, todavia, é apropriada, nos anos 1970, pelo neoliberalismo etc., e assim é confundida. Os movimentos sociais não se reapropriaram do termo mundialização. Daí em diante, fala-se em "globalização", "globalização".

Os debates mais férteis que tive no âmbito da economia política e da sociedade da informação foram com pessoas que trabalham com informação. Nos EUA, as pessoas que mais contribuíram são aquelas, por exemplo, que trabalham em Berkley ou Los Angeles com informação.

Schneider: Por exemplo?

Mattelart: Muitas pessoas que encontrei no início dos anos 2000. Me falha a memória... Agora, estou em contatos com os que trabalham sobre a necessidade da "alfabetização digital".

Schneider: Qual seria o compromisso ético ou ético político da Economia Política da Comunicação?

Mattelart: A primeira coisa é esquecer a Comunicação (risos). A Comunicação, em seu desenvolvimento atual, é perfeitamente aderente à tese do fim da ideologia e do fim da história. Para mim, o problema da comunicação é que ela produz amnésia. Eu creio que há uma forte corrente que esquece a história, a ideologia, as classes sociais, o enfrentamento entre as classes etc. Assim, creio que a primeira ética é voltar a atenção para uma sociedade completamente desigual, onde há injustiças sociais. Esse é o ponto de 
partida para toda ética que trata dos sistemas de comunicação. Quer dizer, nossas sociedades ainda são formadas por classes, etnias, gêneros. Isso me parece essencial. Porque se não reconhecemos esse dado, pouco importa o que dizemos, já que esta é, afinal, a razão de sermos críticos.

Schneider: Estou de acordo (risos). Mas será possível fundamentar esse raciocínio a partir de uma concepção do homem ou da história que possa ser considerada científica? Ou é somente o desejo de um bom coração?

Mattelart: A concepção que tenho da história (e isso é muito importante, a concepção da história)... creio que o perigo existente quando reivindicamos a história é concebê-la a partir de uma visão muito focalizada... especialmente quando toda a história é marcada, por exemplo, pelo ocidentalismo. Eu sou a favor de uma história interconectada. O que isso quer dizer? Falo de uma história global capaz de comunicar, melhor dizendo, conectar diferentes visões de um mesmo fenômeno. Pois creio que é essa a história global, face a uma história antiquada e reacionária. Assim, pode-se relacionar pessoas que vêm de culturas diferentes, que expressam culturas diferentes. Creio que história global é isso: pessoas que falam a partir de diferentes territórios. Isso é importante. Além disso, essa mistura implica também uma diversidade de pontos de vista científicos, o que me parece fundamental. Creio que, de qualquer forma, a construção da ciência se dá a partir do vivido, da vida concreta. Em determinado momento é difícil separar a ciência de política.

Schneider: Alguma indicação bibliográfica para quem quiser se aprofundar nessas discussões?

Mattelart: Claro. Em Comunicação, os livros de Otlet são importantes. O primeiro livro sobre a definição de documento, e depois de informação, é muito importante. Mas já que estamos em Cuba, vou te indicar um livro cubano, de Manuel Fraginals. O livro é muito interessante. É uma história da 
construção da economia do açúcar. Esse livro me inspirou muito, pois mostra como o telégrafo e o cabo submarino, no fim do século XIX, foram determinantes na configuração da bolsa internacional. Esse livro não tem nada a ver com as Ciências da Comunicação, mas, para mim, é a primeira teorização da comunicação na América Latina. É a primeira vez que digo isso. Podemos dizer que os historiadores importaram elementos de reflexão do que é a comunicação a partir de um ponto de vista da economia política crítica... bom, respondido... (risos) mas há também.... é difícil a questão que você me propõe... livros, bibliografias... e eu não te respondo... (mais risos)

Schneider: A Bíblia, O Capital, o que mais?

Mattelart: Os textos de Gramsci sobre os intelectuais. Os textos de Marx sobre introdução à economia política. E eu ouso dizer - porque hoje em dia temos algum medo dele -, há textos fundamentais de Lênin. E o texto de Trotsky sobre a vida cotidiana.

Schneider: Qual?

Mattelart: "Sobre a vida cotidiana".

Schneider: Isso é muito interessante, pois sou professor de um programa de pósgraduação na Universidade Federal Fluminense que se chama Mídia e Cotidiano.

Mattelart: Trotsky é fundamental. Enfim, falo dos "ancestrais" que ensaiaram o desenvolvimento de um marxismo crítico, livre do burocratismo. Isso eu fiz com um escritor americano [Seth Siegelaub] que morreu há três anos. Nós publicamos em inglês uma antologia que se chama "Communication and class strugle". Enfim, reunimos textos sobre comunicação e luta de classes. O primeiro tomo é sobre "imperialismo e capitalismo" e o segundo tomo 
sobre "socialismo". Nós reunimos textos básicos de autores clássicos e textos mais desconhecidos sobre televisão, música etc. É verdadeiramente uma antologia. O primeiro foi publicado em 1979. Esse texto só existe em inglês. Para o espanhol, traduziram apenas minha introdução.

Schneider: Foi algo inovador.

Mattelart: Àquela época, sim. 